\title{
Ciencia y fe en la Edad Media: Gonzalo Hispano, OFM
}

\section{(Science and faith in the Middle Ages: Gonsalvus Hispanus, OFM)}

\author{
MANUEL LÁZARO PULIDO \\ Universidade Católica Portuguesa - C.R. Porto \\ Instituto Teológico de Cáceres (UPSA)
}

Resumen: La cuestión sobre la fe y la ciencia en la Edad Media es muy amplia. Por este motivo presentamos una reflexión que nace de un autor muy significativo en la comprensión del paso que se sucede de la generación que hace frente a los retos del aristotelismo en el siglo XIII y que culminan en el Syllabus de 1277 y la generación que discute en temas concretos referentes a la propia antropología, la cosmovisión del mundo creado y en ello las cuestiones referentes a las bases metafísicas y antropológicas que subyace a la pregunta por el mismo estatuto de la ciencia que se dirime en la confrontación con el argumento de la fe. En este sentido Gonzalo Hispano, maestro de Duns Escoto, ayuda a comprender la recepción de la idea de ciencia en el contexto en el que vive y proyecta la nueva reflexión frente al Aristóteles posterior a las condenas. Nos fijaremos especialmente en la cuestión IX para reflexionar sobre el equilibrio entre ciencia y fe, conocimiento de autoridad y conocimiento científico, ciencia y sabiduría.

Palabras claves: Gonsalvus Hispanus; filosofía medieval; ciencia; fe; opinión; sabiduría; tomismo; pensamiento franciscano.

Abstract. The question about the faith and the science in the Middle Ages is very broad. For this reason, this paper reflects the thoughts of the author which are very significant for the comprehension of transition from the generation who faced the challenges of the Aristotelism in the 13th century and the Syllabus from 1277, to the generation which discussesed several questions related to the anthropological and metaphysical issue. In this respect Gonsalvus Hispanus, Duns Escoto's teacher, helps us to understand the 
reception of the idea of science in the post-condemnation context. We specially pay our attention to the $9^{\text {th }}$ Question in order to consider the relationship between science and faith, knowledge of authority and scientific knowledge, science and wisdom.

Keywords: Gonsalvus Hispanus; medieval philosophy; science; faith; opinion; wisdom; Thomism; Franciscan thought.

1. La relación entre la ciencia y la fe ha sido tan natural como a su vez problemática desde el inicio mismo del pensamiento occidental y de la relación polisémica de la derivación de la expresión por los meandros de los términos (y por lo tanto de los conceptos y de las realizaciones sutiles) de la razón occidental y de las referencias de la palabra y del origen: mitos, épos, logos, donde "la filosofía es una reflexión que se hace en lo que es, en el lenguaje"1. La historia del pensamiento se ha ido desarrollando así dialécticamente entre la epifanía narrativo-simbólica de la mítica (y el lenguaje profético), la manifestación poético-semántica del mundo, y el acceso racional-sintáctico de la filosofía (el estudio del mundo de las cosas) y la ciencia (el estudio de las cosas del mundo). Las tres aproximaciones hablando del mundo, todas proponiendo valores: los de la complejidad del universo humano (Dios, mundo, hombre). Un quehacer de la misma mente humana que no siempre ha sabido ni sabe, ni tiene porqué saber, delimitar, conceptualizar. Siempre ha sido difícil "distinguir para unir”, pues es complicado distinguir y lo es aún más unir. Porque a veces no se puede distinguir, y otras veces no se puede o no se sabe unir.

Pero las dificultades siempre son ocasión para la inteligencia y ocasión de creación de mundos semánticos y sintácticos, de matices. La Edad Media es especialmente una época que afronta los nuevos retos y dificultades: la de la creación (al inicio) y la recreación (al final) del orden de pensamiento de un nuevo mundo y una identidad nueva. Un mundo medieval que crea la identidad occidental tal como la conocemos desde continuos procesos de aculturación. Los siglos XII y XIII son especialmente signi-

1 Manuel Lázaro, "Filosofía antigua: la filosofía como decir”, in Entre filosofía e literatura. Ciclo de Conferências, ed. Maria Celeste Natario y Renato Epifänio (Sintra - Pertual: Zéfiro, 2011), 25. 
ficativos. La riqueza y la dificultad de estos procesos se hacen palpables de forma especial en las condenas universitarias que han suscitado una abundante literatura y que conocen en la precisión entre la fe y la ciencia a uno de sus objetos fundamentales ${ }^{2}$. En esta época de nuevo surge el viejo problema: la dificultad de establecer una barrera, un límite entre ciencia y fe, en términos medievales y a partir de aquí occidentales, entre filosofía natural-ciencia y teología, tanto a nivel material, pues con frecuencia coinciden en dar explicaciones sobre el mismo objeto -como puede ser el hombre o el mundo-; como a nivel metodológico y el alcance de sus explicaciones: utilización de las facultades humanas, significación de las mismas, nivel de acercamiento a la verdad (y en ello comprensión de la verdad), utilización sintáctico-semántica; necesidad de una referencia o grado de realidad de la referencia (inmanencia-trascendencia), disciplinas envueltas (Artes-Teología), tradiciones (platónicas-peripatéticas), metafísicas (del uno y lo múltiple a la metafísica del ser)..., en fin ciencia-sabiduría. La llama que enciende esta reflexión será la que se apague en la Edad Moderna: Aristóteles; el rescoldo que se pretende apagar, la mimética platónica, será el que se encienda siglos más tarde bajo la lectura de la mathesis.

2. Efectivamente, durante el siglo XIII la razón de la ciencia, nacida de la filosofía natural, va imponiéndose (a diversos niveles de intensidad) paulatinamente e introduciéndose en las aulas de las nacidas universidades y por extensión de los centros de estudios. En este debate los franciscanos fueron protagonistas activos, no solo en la elección de una mirada u óptica dentro de las diversas opciones, sino que ellos mismos fueron realizando disputas internas nacidas de un vasto conocimiento de las diferentes disciplinas universitarias y las diversas corrientes ya asentadas a finales del siglo XIII e inicios del siglo XIV. La filosofía cristiana y la filosofía (metafísica y natural) no cristiana (Aristóteles, Avicena) no agotan el saber franciscano. Las ciencias nacidas de las artes liberales, como la geometría, la física, o las

2 Cf. Las condenas de Aristóteles en la Edad Media Latina, coord. Francisco León (Valencia: Kyrios 2013). Una bibliografía en Francisco León, 1277. La condena de la filosofía, estudio preliminar, Traducción del syllabus (Madrid: A parte rei Revista de Filosofía, 2007), 109-114. 
propias del lenguaje y el razonamiento (lógica y gramática especulativa), así como otras más prácticas y fundantes como el derecho canónico o el derecho civil, planean en no pocas especulaciones teológicas. Lejos han quedado aquella trentena de hermanos franciscanos que en el París de 1228 se dedicaban a predicar y convertir las almas antes de que en 1240 se alojaran los hermanos destinados a estudiar en el Convento des Cordeliers. Más tarde en plena discusión entre ciencia y fe, hacia 1280, cuenta el convento parisino con 140 hermanos $^{3}$. Frente a este Studium franciscano se sitúa el Studium Dominicano de Saint-Jacques. En la época en la que Gonzalo Hispano es regente del estudio, este cuenta con 155 hermanos, un número a tener muy en cuenta toda vez que el estudio dominicano tiene 132 hermanos, regidos por hermanos de gran altura intelectual, así en el año académico de 1302-1303, las cátedras de los dominicos son ocupadas por Dietrich de Freiberg ${ }^{4}$ y Juan Eckhart, (Maestro Eckhart) ${ }^{5}$. En concreto, este último, mantuvo con el maestro Gonzalo Hispano un famoso debate epistemológico sobre la primacía del intelecto o de la voluntad en el que subyace una caracterización del debate ciencia y fe, y donde se evidencian las discrepancias antropológicas subyacentes a estas cuestiones epistemológicas.

3. El número elevado de hermanos en el estudio parisino en tiempos de la regencia del maestro Gonzalo es el resultado de la evolución de la Orden y la importancia dada al estudio e impulsada por Buenaventura siendo

3 John Richard Humpidge Moorman, A History of the Franciscan Order from its Origins to the Year 1517 (Oxford: Clarendon Press, 1968), 132.

4 Cf. Kurt Flasch, Dietrich von Freiberg. Philosophie, Theologie, Naturforschung um 1300 (Frankfurt am M.: Klostermann, 2007).

5 Cf. Voici Maître Eckhart, Textes et études, dir, Emilie Zum Brunn (Grenoble: Jérôme Millon, 1994). Respecto su obra traducida en francés ver una selección bibliográfica de Benoît Beyer de Ryke, Maître Eckhart (Paris: Entrelacs, 2004). Una presentación y análisis de los trabajos sobre el místico renano en las dos últimas décadas del siglo XX en los siguientes artículos: Nikiaus Largier, “Meister Eckhart, Perspektiven der Forschung, 1980-1993”, Zeitschrift für deutsche Philologie 114 (1995): 29-98; Id., "Recent work on Meister Eckhart, positions, problems, new perspectives, 1990-1997”, Recherches de théologie et philosophie médiévale 65 (1998): 147-167; Id., “Recent Publications on Eckhart”, Eckhart Review 7 (1998): 55-58. Una bibliografía completa desde 1800 hasta la fecha de la publicación de la obra en Id. Bibliographie zu Meister Eckhart (Fribourg (Suisse): Universitätsverlag Freiburg, 1989). 
General de la Orden Franciscana y que supone un impulso para todos los rincones de la geografía cristiana en la que la Orden de Hermanos Menores estaba presente. La provincia de Santiago, de donde proviene Gonzalo Hispano, es un ejemplo de la estructuración reglada de los estudios dentro de la Orden. Dicha enseñanza exigía para la obtención del grado de Bachillerato conocimientos de la obra aristotélica en el terreno filosófico. Este era un paso previo a los estudios teológicos basados en la lectura de la Biblia y el comentario a la obra de las Sentencias de Pedro Lombardo. Esta exigencia de formación tuvo sus frutos en la presencia de hermanos de la Orden en los diferentes ámbitos pastorales tanto en la predicación del pueblo cristiano como en la Corte (Alfonso X, el Sabio en la Corona de Castilla ${ }^{6}$ ), reflejándose en la presencia de hermanos destacados en las aulas parisinas. Es el caso de Gonzalo Hispano, uno de los trece hermanos de la Península Ibérica graduados en París ${ }^{7}$.

En París las facultades de artes y teología tienen una preponderancia frente a las de medicina y derecho canónico más presentes en otros lugares (Montpellier y Bolonia, respectivamente). La cuestión de la ciencia y la fe se desenvuelve por estos lugares intelectuales. Igualmente debemos tener en cuenta que, como señala Olivier Boulnois, hemos de olvidar los clichés en los que con frecuencia estamos rodeados, como el de la servidumbre de la filosofía medieval o el enfrentamiento entre filosofía y teología, reduciendo todo un fenómeno de construcción global de pensamiento occidental a una lucha institucional, que no deja de ser importante, pero que ni tan siquiera ella puede ser reconstruida históricamente si no se tiene en cuenta el marco común en el que se erigió el pensamiento racional compartido ${ }^{8}$.

6 Cf. Luis García, “Naturaleza y ciencia en la Castilla del siglo XIII. Los orígenes de una tradición: Los studia franciscano y dominico de Santiago de Compostela (1222-1230)”, Arbor abril-mayo (1996): 69-125.

7 Cf. Isaac Vázquez, "Repertorio de franciscanos españoles graduados en teología durante la Edad Media”, in Repertorio de Historia de las ciencias eclesiásticas en España, vol. III (Salamanca: Universidad. Pontificia de Salamanca, 1971), 235-320.

8 "Nous vivons environnés de clichés. Celui de la servitude de la philosophie au Moyen Âge et de son affrontement permanent avec la théologie n'est pas le moindre. Pourtant, avant d'être le temps de leur affrontement institutionnel, le Moyen Âge occidental a inventé ces deux pôles. Il a inventé l'enseignement universitaire de la philosophie, et fondé la 
Los matices se refieren, con frecuencia -y en cierta forma ya se ven en Buenaventura-, no tanto a una cuestión sobre filosofía y teología, o razón y fe (ciencia-fe), cuanto al lugar que tiene que ocupar la filosofía (natural...) en el quehacer teológico. El debate, no obstante, modifica, en cierta forma, la mentalidad de los maestros franciscanos y su modo de entender la teología. Siguiendo la estela de las condenas de 1277 se introducen una serie de disputas intelectuales (y en cierta forma espirituales) que afectan los aspectos filosóficos y teológicos y en el que se refleja la pregunta por la legitimidad de las formas de conocimiento y la jerarquía del acceso a la verdad y sus límites (fe-ciencia). Esta cuestión no es meramente intelectual en cuanto que su resolución afectará a las diversas interpretaciones posteriores, a las realidades concretas que se estudien y que poseen una significación de naturaleza antropológica (realidades estructurales y espirituales).

4. Gonzalo Hispano ${ }^{9}$ durante su tarea de maestro regente en París mantiene disputas intelectuales que se recogen tanto en sus Quaestiones disputatae -de las que se conocen dos redacciones: Quaestiones Avenionensis (16 q.) y Quaestiones Trecenses (5)- ${ }^{10}$, y las Quaestiones quodlibetali. Las Disputationes fueron debatidas en París, en el 1302-1303. En ellas se deja ver un intenso debate de ideas a tenor de la variedad de autores con los que se dialoga: Alejandro de Hales, San Buenaventura, Sto. Tomás de Aquino, Godofredo de

théologie comme science. Ne voir que le conflit des facultés et des disciplines, c'est s'en tenir à un phénomène de surface, négliger le cadre commun qui le rend possible, l'enracinement dans une même rationalité". Olivier Boulnois, "Philosophie et théologie. Pourquoi cette dualité ?”, IESR - Institut européen en sciences des religions, última modificación: el 15 de junio de 2009. Disponible en URL : http://www.iesr.ephe.sorbonne.fr/index4493.html. Consultado el 29 de enero de 2014.

9 Un retrato de su vida en Manuel Lázaro, Gonzalo Hispano, Arqueología, historia y viajes sobre el mundo Medieval 42 (2012): 40-49. Cf. León Amorós “Introductio Historico-critica”, in Gonsalvus Hispanus, Quaestiones Disputatae et de Quodlibet, ed. León Amorós con introducción histórico-crítica, Firenze: Quaracchi, 1935, pp. XVI-XVIII.

10 En la edición crítica de León Amorós las Quaestiones Avenionensis, es decir las encontradas en el Códice 1071 de la Biblioteca Municipal Avenionensis, se deoniman Quaestiones disputatae y las Quaestiones Trecenses, es decir las halladas en el Códice 661 de la Biblioteca Municipal Trecensis y al parecer redactadas anteriormente, las llama Quaestiones disputatae secundum aliam reportationem. Seguiremos esta designación. Amorós, "Introductio", LII-LXI. 
Fontaines, Enrique de Gante, Pedro Olivi, Guillermo de la Mare, Ricardo de Mediavilla, Juan Mincio (o de Murrovalle), Juan el Sabio, Maestro Eckhart, Juan de París o Pedro de Alverna ${ }^{11} \ldots$ y en la base las tradiciones agustinista y aristotélica y en ello sus intérpretes no cristianos (Avicena y Averroes respectivamente).

En este contexto aparece una cuestión sobre la función de la filosofía y la teología y la reformulación de la capacidad cognoscitiva de la filosofía en relación a la teología. Esta cuestión es tratada implícitamente a lo largo de la obra de Gonzalo Hispano. En otros escritos nos hemos centrado en la cuestión V de las Quaestiones disputatae, "donde el maestro franciscano se interroga sobre si la alabanza mental a Dios es un acto del intelecto práctico"12. Esta cuestión V centra su análisis en la disputa entre las facultades del entendimiento y la voluntad en las que se conecta la relación entre ciencia y fe. La cuestión que nos ocupa y nos sirve de base para esta breve reflexión y que lleva por título Sobre si el conocimiento adquirido por medio de una autoridad es compatible en si mismo con el conocimiento científico ${ }^{13}$, supone una pregunta sobre la compatibilidad entre el conocimiento nacido de la epistemología nacida de la filosofía natural y la naturaleza y alcance epistemológico de la tradición. La cuestión es un reflejo del debate universitario entre el peso que han de tener la fe y la razón en la elaboración teológica ${ }^{14}$. Gonzalo Hispano repara en la relación entre la gradación epistemológica: opinión, fe y ciencia.

5. La disputa inicia con la respuesta negativa, que niega la compatibilidad entre ambas formas de conocimiento. Más tarde las rebatirá, por lo que Gonzalo se sitúa en una postura que intenta equilibrar las posiciones intelectualistas y místicas. Los horizontes filosóficos y teológicos son los delimitados de forma paradigmática en el horizonte de Tomás de Aquino, Enrique de Gante y Godofredo de Fontaines. Gonzalo Hispano no se sitúa,

11 Amorós, “Introductio”, LXV.

12 Manuel Lázaro, "Filosofía y teología en Gonzalo Hispano. Contribución hispana en el año de Juan Duns Escoto", Revista de Hispanismo Filosófico 13 (2008): 45.

13 Utrum cognitio habita per auctoritatem compatiatur secum cognitionem scientificam

14 Cf. Carlos Mateo, La construcción de la ciencia en la universidad medieval. Apuntes acerca del debate epistemológico en el siglo XIII (Córdoba: Brujas, 2005). 
sin embargo, equidistante entre ellos. Y se sentirá más cercano, de forma crítica, a Enrique de Gante que a Godofredo de Fontaines, aunque huyendo de toda forma de intelectualismo.

La cuestión tiene como telón de fondo la tematización de Tomás de Aquino tratada en el Comentario al De Trinitate de Boecio y en la Summa Theologie sobre la subordinación o dependencia de las ciencias entre sín ${ }^{15}$. Esta es una cuestión, presentada con anterioridad por otros teólogos como Roberto Grosseteste, Guillermo de Auxerre o Buenaventura. Se intenta poner en relación las distintas ciencias y su jerarquización (o dependencia) de modo que se pueda establecer qué ciencias (propter quid) son más perfectas en el sentido de no depender de otras (subalternantes) y cuáles mantienen (quia) una dependencia (subalternadas). En el orden de los fines, para Tomás de Aquino, siguiendo la doctrina aristotélica, la ciencia subalternante apunta a un fin superior a la subalternada. Por su parte, también atendiendo a la doctrina aristotélica por la que la verdad debe ser evidente, bien por sí misma, bien por deducción de otra verdad que es evidente en sí, Tomás expone que en orden a los principios hay ciencias (subalternadas) que reciben de otras (subalternantes) sus principios. Por último existe una relación de dependencia (subalternante-subalternada) cuando el sujeto de una ciencia depende del objeto de otra. La teoría del maestro dominicano establece así una jerarquización epistemológica que afecta a las formas de conocimiento y ciencia y en ella a la ciencia teológica, no solo en su dimensión especulativa, sino también a la autoridad de la Sagrada Escritura, una autoridad de la revelación en la discusión teológica que quiere determinarse como discurso de ciencia. Efectivamente, Tomás de Aquino había puesto negro sobre blanco una posición de lectura de Aristóteles donde la autoridad de la Sagrada Escritura, la doctrina sagrada, ocupaba, como no podía ser de otra forma, un rango superior, de modo que guiaba el resto de las ciencias ${ }^{16}$. Y la utilización de la palabra "ciencia” no está puesta por casualidad ni al azar. El contenido de la revelación divina

15 Cf. Marie-Dominique Chenu, La theologie comme science au XIIIe siecle, $3^{\mathrm{a}}$ ed. (Paris: J. Vrin, 1969), 104-105.

16 Thomas Aquinas, Sententias, prol., a.1: “Imperat omnibus tamquam principalis”. 
desarrollada como doctrina sacra se constituye una ciencia, una disciplina que tiene su especificidad científica. La teología, por su parte, desarrolla de forma más específica la fuerza del raciocinio, donde los artículos de la fe operan como principios, evidentes para Dios y no para el hombre, en su conocimiento imperfecto; pero que orgánicamente funcionan como los principios evidentes de las ciencias racionales. De esta forma, Tomás de Aquino propone, desde la articulación científica de Aristóteles, que es posible, desde la ordenación del saber conforme a la gracia de la naturaleza y su capacidad de perfección, el hecho de que la razón y la fe tengan una relación armoniosa, en concordancia, es decir, que sean compatibles. Ambas son distintas, pero no separadas:

La doctrina sagrada es ciencia. Hay dos tipos de ciencias. 1) Unas, como la aritmética, la geometría y similares, que deducen sus conclusiones a partir de principios evidentes por la luz del entendimiento natural. 2) Otras, por su parte, deducen sus conclusiones a partir de principios evidentes, por la luz de una ciencia superior. Así, la perspectiva, que parte de los principios que le proporciona la geometría; o la música, que parte de los que le proporciona la

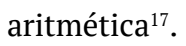

6. En este contexto Gonzalo repara en Enrique de Gante y Godofredo de Fontaines. En primer lugar establece una metáfora entre visión y grado de conocimiento, en clara alusión a la opinión de Enrique de Gante, para quien la ciencia trata de lo visible y la fe de lo invisible de modo que teniendo objetos diferentes no pueden coincidir: "si el conocimiento adquirido por la autoridad estuviera sostenido al mismo tiempo por la ciencia, sucedería que ambas se ocuparían de lo visible y de lo no visible, lo cual es imposible” ${ }^{18}$. Efectivamente para el teólogo belga es el modo de adquisición del objeto lo que define la fe, en este caso la visión que hace de la teología su carácter de ciencia adquirida en virtud a un estado intermedio entre la fe (lumen fidei) y la gloria (lumen gloriae). Esta luz intermedia (lumen medium) permite in via que la verdad cristiana del hombre caminante sea verdadera

17 Thomas Aquinas, Summa theologiae, I, q.1, a.2, resp.

18 Gonsalvus Hispanus, Quaestiones disputatae, q. IX, 1, 133. 
ciencia, toda vez que es imposible el entendimiento de los principios que sustentan la teología ${ }^{19}$. Enrique de Gante opera una reducción que hace que la teología exagere su carácter in via de modo que la teología, a su vez, se muestra superior a la fe del creyente. De esta forma asume en la autoridad la razón (teológica) como lugar intermediario hacia la visión de Dios. La autoridad es un camino de progresión que va de la Sagrada Escritura a los Padres de la Iglesia, pasando por los Apóstoles manifestando así la inteligencia de la fe. De esta forma la teología es, en primer lugar, autoridad: Sagrada Escritura ${ }^{20}$. Esta teoría parece estar presente en la argumentación contraria a la negación de la compatibilidad entre autoridad y ciencia (fe y razón) en Gonzalo Hispano cuando afirma que efectivamente la luz mayor como la del Sol parece obscurecer o ofuscar la menor como la de una candela cuando se ilumina un objeto. En ese momento -sigue con la metáfora el maestro franciscano- la luz en sí no se ofusca, sino que una conserva mejor la otra. De esta forma, por comparación a nuestros sentidos (recuerda aquí a Aristóteles) lo que es más sensible no aprehende de lo menos sensible y recíprocamente pasa con el intelecto. Luego, de forma similar, la luz espiritual, que se adquiere por medio científico comparte con la luz menos clara que es la luz de la fe, y esto respecto del mismo objeto ${ }^{21}$. El Doctor Solemnis afirma desde su neoagustinismo pasado por el tamiz del aristotelismo y la filosofía de Avicena que la teología es ciencia al fundarse en un tipo de conocimiento cierto, una certeza que supera la opinión y que le lleva al conocimiento evidente. Se separa así de la opinión de Godofredo de Fontaines, que Gonzalo también afrontará, y abunda en el carácter especulativo de la teología concluido por Tomás de Aquino al afirmar que "estamos ante una ciencia más especulativa que práctica”22. La teología, a pesar del intelectualismo, es una ciencia que unifica el saber, una ciencia general que

19 Cf. Rebo Tyorinoja, "Lumen medium. Henry of Ghent on the Accessibility of Theological Truths", in Medieval Philosophy and Modern Times, ed. Guita Holmström-Hintikka (Dordrecht-Boston-London: Kluwer Academic Publishers, 2000), 161-182.

20 Henricus Gandavensis, Summa quaestionum ordinariarum. Paris: Iodocus Badius Ascensius 1520 - repr. Anastática New York: St. Bonaventure, 1953.

${ }_{21}$ Gonsalvus Hispanus, Quaestiones disputatae, q.IX, ad op. 1, 137.

22 Thomas Aquinas, Summa theologiae I, q.1, a.4, resp. 
apunta a la sabiduría ${ }^{23}$ diferente de la ciencia restrictiva; es una ciencia que se sitúa "por encima de las ciencias humanas” y que puede ser entendida de forma absoluta como ciencia ${ }^{24}$. La autoridad teológica se impone a la razón como forma sapiencial del conocimiento, pero Enrique no sólo diferencia y ordena a la teología, sino que resuelve el conocimiento en teología, de modo que esta se presenta como una ciencia única, los objetos de las otras ciencias quedan, en parte, subsumidos en el objeto de la teología ${ }^{25}$.

7. El otro interlocutor, Godofredo de Fontaines, se sitúa contra el equilibrio de la filosofía y la teología, al no ver mostrado en Enrique de Gante la mediación de la $\operatorname{luz}^{26}$. Ambas ciencias no se relacionan, son disciplinas diferenciadas. Los filósofos, los artistas de la razón, realizan un gran esfuerzo por armar científicamente su disciplina, mientras que los teólogos olvidan con frecuencia el ejercicio de la razón, animados por la autoridad de la revelación y no se puede sacar una ciencia demostrativa sino es mediante premisas demostradas, pues la conclusión se relaciona con sus premisas, unas premisas basadas en las creencias dan como resultado una conclusión sustentada en la creencia ${ }^{27}$. La teología es una ciencia demostrativa, de esta forma Godofredo de Fontaines realiza una defensa de la racionalidad filosófica. Aparece como un racionalista, los argumentos más importantes se los concede a la razón filosófica, dejando el argumento teológico como una forma secundaria, si acaso necesaria para combatir otras posiciones. Esta forma de aristotelismo, que no solo es material, sino formal, se ve especialmente en la cuestión que está en la base de muchas polémicas: la de la pluralidad de las formas. Es la disputa que sucede en Gonzalo Hispano a la cuestión $I X$, y es la que obliga a hacer una pregunta sobre el equilibrio

${ }^{23}$ Cf. Josep M. Rovira, “Sobre el mètode teològic en Enric de Gand”, Revista catalana de teología 8 (1983) 191-202.

24 Henricus Gandavensis, Summa quaestionum ordinariarum, a.7, q.3, 114: "Absolute igitur dicendum quod theologia est scientia”.

25 Henricus Gandavensis, Summa quaestionum ordinariarum, a.7, q.4, 132 "Absolute dicendum est quod primo modo subalternationis theologia omnes alias scientias sibi subalternat”.

26 Godefridus de Fontibus, Quodlibet VIII, q.7, ed. M. de Wulf et alii, Publications Universitaires, Louvain 1904-1937, vol. IV, 69-71, 77-79.

27 Godefridus de Fontibus, Quodlibet IV, q.7, 262. 
de la filosofía y la teología, sobre sus fuentes (razón y autoridad), sobre sus posibles interferencias o retroalimentaciones, es decir, su compatibilidad. Godofredo de Fontaines apuesta por la filosofía, por la razón, por la pluralidad de formas, por el aristotelismo, y, por lo tanto, por una metodología especialmente racional. No se niega la teología, sino una teología arbitraria, basada en la creencia común (la del vulgus), que determina lo que va "contra la fe" ${ }^{28}$. La teología se muestra así como un saber que depende de la adhesión de la fe a la autoridad revelada. Y aunque en principio esto no significa, al decir de Leonardo Sileo, que la teología y la ciencia demostrativa son, para Godofredo, por sí incompatibles, en el sentido de que puedan darse las dos, sí son, sin embargo "modalidades autónomas del saber y en cierto modo complementarias" 29 . Esto supone que la naturaleza estudiada por la filosofía con las armas de la razón y la demostración adquiere un mayor conocimiento y una voz más autorizada que la de la "autoridad" teológica, en cuanto que no contradice la naturaleza ni se basa en ficciones alejadas de la ciencia ${ }^{30}$. La opinión de Godofredo de Fontaines ${ }^{31}$ basada en la tradición del siglo XII (Hugo de San Víctor) auxilian al maestro franciscano en la consecución de su conclusión sobre la compatibilidad de las diversas formas de conocimiento: opinión, fe y ciencia. Así señala la objeción a la teoría de la compatibilidad desde la posición de que la autoridad de la Sagrada Escritura se apoya en la fe. Siendo que la fe no es opinión ni ciencia. Es un término medio que no puede tender a los extremos ${ }^{32}$.

Gonzalo Hispano recuerda otro argumento contrario de naturaleza epistemológica a partir de una glosa de san Pablo (1 Co 13,10). Se refiere al tipo de conocimiento de la razón y la ciencia, y de la fe. Su modo diverso imposibilita su adecuación. Ya mencionada antes en la referencia breve

28 Godefridus de Fontibus, Quodlibet II, q.7, 125-127.

29 Leonardo Sileo, Fabio Zanatta, "I maestri di teologia della seconda metà del Duocento", in Storia della Teologia nel Medioevo. III La teologia delle scuole, Dir. Giulio d'Onofrio, (Casale Monferrato (AL): Ed. di Piemme, 1996), 81.

30 Godefridus de Fontibus, Quodlibet IV, q.10, 262: "Et hoc est dicere contradictoria et multum derogare sacrae theologiae et doctoribus ipsius, tales fictiones de ipsa theologia attractantibus ipsam propalare"

31 Godefridus de Fontibus, Quodlibet VIII, q. 7.

32 Gonsalvus Hispanus, Quaestiones disputatae, q.IX, non 2, 134. 
al Aquinate, se recuerda que el conocimiento científico es conocimiento claro y perfecto, por que es conocimiento por causas. Mientras que el conocimiento que nace de la fe es incompleto ya que al nacer en un estado de imperfección provoca que el conocimiento actual, desde la fe, sea parcial. Gonzalo, recordando a Godofredo de Fontaines, de la mano de su discípulo, Juan de Polliaco -la voz contemporánea de esta visión- ${ }^{33}$, expresa lo que significa e implica llevar a Tomás de Aquino y sus puntos de vista a consecuencias que van más allá en la apuesta por el entendimiento en una rígida apuesta interpretativa de la epistemología aristotélica.

Resulta interesante también el argumento que recuerda Gonzalo Hispano relativo a la ordenación de las ciencias. El objeto y la claridad del conocimiento difiere entre la ciencia y la fe. El conocimiento por la fe implica una mayor gracia que el de la ciencia. Si tuviéramos en cuenta la finalidad diríamos que las ciencias se orientan a la fe en cuanto al objeto. Pero esta argumentación tiene en cuenta la claridad y evidencia epistemológica por lo que teniendo en cuenta la evidencia decimos que es la fe la que se ordena a la ciencia; de este modo en cuanto que la fe se ordena a un conocimiento más objetivo posible, pero en cuanto tenemos conocimiento de la ciencia cesa el de la fe.

8. Si la posición de Enrique de Gante desembocaba en la imposibilidad real de un conocimiento filosófico, en cuanto que todo se reduce a un objeto que tiene como lugar de sabiduría el de la teología, donde la razón es razón teológica, alimentada por la fe; y la de Godofredo de Fontaines llevaba a la minusvaloración teológica y de la autoridad, fundado en dos saberes con dos objetos diferentes y casi incompatibles, Gonzalo Hispano aboga por una compatibilidad de las diferentes formas de adquisición epistemológica, con la sola objetiva incompatibilidad entre la fe y la visión beatífica ("se prueba doblemente que ni la fe ni un acto de fe pueden ser compatibles

33 Cf. Ludwig Hödl, “Die Unterscheidungslehren des Heinrich von Gent in der Ausein-andersetzung des Johannes de Polliaco mit den Gandavistae”, in Henry of Ghent and the Transformation of Scholastic Thought: Studies in Memory of Jos Decorte, eds. Guy Guldentops, Jos Decorte, Carlos G. Steel (Leuven: Leuven University Press, 2003), 371-386. 
-según lo que creemos en vía- con una santa visión”34), en cuanto a la situación in via e in patria, la oscuridad de la primera y la claridad de la segunda, aún así por gracia también en posibilidad de ser solventada por la potencia absoluta de Dios (de potentia Dei absoluta) como en el caso ya mencionado de san Pablo quien viendo lo perfecto mantuvo su fe:

También afirma San Agustín que Pablo, durante su cautiverio, tuvo una visión de la esencia divina y de todos los artículos de la fe y que supo con seguridad que después de aquella visión no perdería la fe $\mathrm{f}^{35}$.

Cuando se argumenta que según el Apóstol cuando llegue lo perfecto desaparecerá lo parcial hay que decir que el Apóstol habla de lo que sucede de facto con la fe no de aquello que es posible con respecto a la potencia absoluta de $\operatorname{Dios}^{36}$.

Gonzalo Hispano responde en este contexto mediante la búsqueda del equilibrio. Como vemos se sitúa en la posición de los grandes maestros, por sus interlocutores en Tomás de Aquino, para negar las correcciones exageradas de su posición y la negación de sus extremos iluministas. Algunos, afirma, dicen que la fe y la ciencia no tiene conexión en sí en cuanto a su objeto, y aunque son diferentes en su objeto pueden complementarse ${ }^{37}$, no por su naturaleza sino por su mérito.

Su equilibrio nace en la argumentación contraria que es parte de la conclusión. Por una parte, la razón nacida de la opinión no es concluyente. En este sentido Gonzalo Hispano propone el equilibrio de la opinión de la ciencia. Si la autoridad de la fe es disminuida por el componente de la creencia, también hay que admitir que si en la ciencia hay visos de creencia debería ser también rechazada. Es decir, en la ciencia hay opinión, en el sentido en que no siempre se afirma lo que los efectos indican. Siendo así

34 Gonsalvus Hispanus, Quaestiones disputatae, q.IX, sol.III, B, 8, 159.

35 Gonsalvus Hispanus, Quaestiones disputatae, q.IX, sol.III, B, 6, 156-157. Gonsalvus Hispanus, Quaestiones disputatae, q.IX, sol.III, A, 1, 144: "La opinión coexiste con la fe y la ciencia; lo segundo por que la fe coexiste con la ciencia; lo tercero porque ninguna de las dos cosas, ni la fe ni la opinión, coexiste de hecho con una visión santa; lo cuarto porque esto es posible en relación a la absoluta potencia de Dios

36 Gonsalvus Hispanus, Quaestiones disputatae, q.IX, sol. obj. 4, 163.

37 Gonsalvus Hispanus, Quaestiones disputatae, q.IX, sol., 139. 
que la ciencia es ciencia de causas (y efectos), luego existe una similitud en la opinión. Por lo que podemos señalar que si tenemos conocimientos parciales en la naturaleza e indicamos que hay ciencia, al hablar de Dios, aunque existan limitaciones desde la visión natural esto no implica que no haya ciencia. Por lo que la autoridad y la razón coinciden desde el conocimiento contingente desde ciencia. Ciencia y fe comparten cierta inestabilidad epistemológica que hacen que no sean contradictorias, si bien difieren en la potencia cognoscitiva ${ }^{38}$. Resulta interesante esta limitación racional de la teología especulativa y la equidistancia con la fe.

Por otra parte Gonzalo Hispano hace coincidir la posibilidad de realizar ciencia y fe respecto del objeto de la teología, mediante la visión:

también es algo patente el que los ángeles antes de su confirmación y el hombre antes del pecado tuvieron un conocimiento más claro de que Dios existe, de que Dios es uno y quizá incluso de que Dios es uno y trino, conocimiento este sobre estas cosas o sobre cualquier otra conclusión que nosotros alcanzamos en vía gracias a nuestra ciencia. Por tanto, si la fe es compatible con su conocimiento, tal como estos han dicho con anterioridad, resulta evidente entonces que la fe puede coexistir con la ciencia con la que contamos en vía ${ }^{39}$.

Creer que Dios es uno y trino puede ser mostrado por la ciencia demostrativa, pero también por el propio temor de Dios, por el amor a Dios en cuanto que "nisi amatur nisi cognitum, correspondens non est nisi cognitio per auctoritatem sacrae Scripturae; ergo cum scientia perfecte postes stare cognitio", citando así la autoridad de Alejandro de Hales, la forma de la Visio Dei como forma de conocimiento humano. Gonzalo Hispano, tras las sistematizaciones de Alberto Magno y Tomás de Aquino y los comentarios posteriores de Gil de Roma o Godofredo de Fontaines y las reacciones de Enrique de Gante, y desde la tradición franciscana que nace de Buenaventura, en un camino cierto de equilibrio, pero en una equidistancia con una doctrina aristotélica ya, si bien condenada, en parte asentada (y por ello precisamente cuestionada), reutiliza la razón en una mirada desde la visio

38 Gonsalvus Hispanus, Quaestiones disputatae, q.IX, sol.I, 1-4, 140-142; 144.

39 Gonsalvus Hispanus, Quaestiones disputatae, q.IX, sol.III, B, 7, 158-159. 
Dei, apuntando a elementos de filosofía especulativa y de teología práctica, que lleva en lo profundo de su motivación de la defensa de la validez de la doctrina cristiana. De esta forma realiza una lectura del Halense que conduce hacia la voluntad, pues como señala Aleksander Horowski, si la gracia se refiere principalmente al intelecto, la caridad lo hace, en el Halense, especialmente a la voluntad, teniendo en cuenta que la caridad (el amor) es entendida como "forma" de la virtud de la caridad. De esta forma la discusión de la razón y la fe, razón y autoridad, el acceso de la fe hacen en la voluntad lo que la gracia (de la visión) a la ciencia que nace del intelecto. Ambas comparten en diferentes facultades la capacidad de decir ${ }^{40}$. Gonzalo Hispano va abriendo paso a la facultad de la voluntad como lugar de teología (especialmente práctica) como muestra en sus conclusiones:

En consecuencia, siendo Dios un objeto voluntario que voluntariamente se muestra a los que quiere y cuando quiere, es posible contemplarlo claramente en si mismo y de forma oscura en sus creaturas, tal como sucede cuando un ojo contempla un rostro en si mismo o lo ve reflejado en un agua turbia donde no se ve con claridad. Así, en una santa visión es posible contemplar por medio de su omnipotencia la misma esencia de Dios, en sí y de forma oscura. De esta forma, gracias a la luz de la fe se contempla la esencia de Dios en la oscuridad de sus creaturas. Queda así claro que no supone una contradicción el que la fe y su acto coexistan simultáneamente con una visión betífica ${ }^{41}$.

Gonzalo prepara el camino que afecta a la función especulativa o práctica de la teología de una forma más firme, y dentro de la función contemplativa de la Verdad de Dios, a la finalidad de la misma. Se hace presente en el seno intelectual de la Orden franciscana como respuesta a la cuestión de fondo una síntesis que "Frente a los avances cada vez más profundos de la razón aristotélica en el campo de la teología, crecía el primitivo temor de que el muro de la ciencia se elevara «ultra coelum et coelestia», como había expresado ya, hacia mediados del siglo XIII, Juan de Parma, antece-

40 Aleksander Horowski, La Visio Dei como forma della conoscenza umana in Alessandro di Hales (Roma: Istituto Storico dei Cappuccini, 2005), 227.

41 Gonsalvus Hispanus, Quaestiones disputatae, q.IX, sol.III, D, 2, 162. 
sor de San Buentaventura" ${ }^{42}$; se trata de que la ciencia teológica desde la revelación teológica que nos lleva a la contemplación como fin o que sea capaz de mover al hombre a la fruición de Dios. Un episodio de amor a la verdad teológica en la escuela franciscana del siglo XIII, que tiene siempre en su fidelidad una suspicacia frente al intelectualismo y prepara la síntesis del Doctor Sutil, en un autor tan importante como frecuentemente olvidado, un franciscano que supone una contribución en la universalidad del pensamiento desde la Península Ibérica, de la provincia de Santiago.

Volvemos al principio, a la cuestión sobre la desvelación de la realidad y a la multiplicidad siempre incesantes de las formas antropológicas del descubrimiento de la realidad, una vuelta al origen del propio pensamiento filosófico donde la expresión religiosa se presenta como impulsora etiológica de la filosofía, cuando, en palabras de Olof Gigon, "la religiosidad personal de Hesíodo es el origen de la filosofía, por cuanto se propone la exposición de la verdad y no hacer poesía sencillamente”43. En ese momento se plantea la pregunta entre verdad divina y opinión humana. Una cuestión que aún no se ha resuelto y que deviene cada vez más distante ante el alejamiento mental de los universos empíricos y proféticos en el campo de la ciencia, pero cada vez más cercanos en el de la existencia del hombre.

\section{Referencias}

Andrés, Melquiades. Historia de la Teología Española I. Desde sus orígenes hasta fines del siglo XVI. Madrid: Fundación Universitaria Española, 1983.

Beyer de Ryke, Benoît. Maître Eckhart. Paris: Entrelacs, 2004.

Boulnois, Olivier. “Philosophie et théologie. Pourquoi cette dualité ?”, IESR - Institut européen en sciences des religions, última modificación: el 15 de junio de 2009. Disponible en http://www.iesr.ephe.sorbonne.fr/index4493.html. Consultado el 29 de enero de 2014.

42 Melquiades Andrés, Historia de la Teología Española I. Desde sus orígenes hasta fines del siglo XVI (Madrid: Fundación Universitaria Española, 1983), 475.

43 Olof Gigon, Los orígenes de la filosofía griega. De Hesíodo a Permenides (Madrid: Gredos, 1985), 20. 
Chenu, Marie-Dominique. La theologie comme science au XIIIe siecle, $3^{\mathrm{a}}$ ed. Paris: J. Vrin, 1969.

D’Onofrio, Giulio, dir. Storia della Teologia nel Medioevo. III La teologia delle scuole. Casale Monferrato (AL): Ed. di Piemme, 1996.

Flasch, Kurt. Dietrich von Freiberg. Philosophie, Theologie, Naturforschung um 1300. Frankfurt am M.: Klostermann, 2007.

García, Luis. "Naturaleza y ciencia en la Castilla del siglo XIII. Los orígenes de una tradición: Los studia franciscano y dominico de Santiago de Compostela (1222-1230)”. Arbor abril-mayo (1996): 69-125.

Gigon, Olof. Los orígenes de la filosofía griega. De Hesíodo a Permenides. Madrid: Gredos, 1985.

Godefridus de Fontibus, Quodlibet, editado por M. de Wulf et alii. Louvain : Publications Universitaires, 1904-1937.

Gonsalvus Hispanus, Quaestiones Disputatae et de Quodlibet, editado por León Amorós. Firenze: Quaracchi, 1935.

Henricus Gandavensis, Summa quaestionum ordinariarum. ed. Iodocus Badius Ascensius.

Hödl, Ludwig. "Die Unterscheidungslehren des Heinrich von Gent in der Ausein-andersetzung des Johannes de Polliaco mit den Gandavistae”. In Henry of Ghent and the Transformation of Scholastic Thought: Studies in Memory of Jos Decorte, editado por Guy Guldentops, Jos Decorte, Carlos G. Steel), 371-386. Leuven: Leuven University Press, 2003.

Horowski, Aleksander. La Visio Dei como forma della conoscenza umana in Alessandro di Hales. Roma: Istituto Storico dei Cappuccini, 2005.

Largier, Nikiaus. Bibliographie zu Meister Eckhart. Fribourg (Suisse): Universitätsverlag Freiburg, 1989.

- “Meister Eckhart, Perspektiven der Forschung, 1980-1993”. Zeitschrift für deutsche Philologie 114 (1995): 29-98.

- "Recent work on Meister Eckhart, positions, problems, new perspectives, 1990-1997”. Recherches de théologie et philosophie médiévale 65 (1998): 147-167.

- “Recent Publications on Eckhart”. Eckhart Review 7 (1998): 55-58.

Lázaro, Manuel. “Filosofía y teología en Gonzalo Hispano. Contribución hispana en el año de Juan Duns Escoto”. Revista de Hispanismo Filosófico 13 (2008): 31-52.

- “Filosofía antigua: la filosofía como decir”. In Entre filosofía e literatura. Ciclo de Conferências, editado por Maria Celeste Natario y Renato Epifänio, 25-36. Sintra - Pertual: Zéfiro, 2011.

- Gonzalo Hispano, Arqueología, historia y viajes sobre el mundo Medieval. 42 (2012): 40-49. 
León, Francisco. 1277. La condena de la filosofía, estudio preliminar, Traducción del syllabus. Madrid: A parte rei Revista de Filosofía, 2007.

León, Francisco, coord. Las condenas de Aristóteles en la Edad Media Latina. Valencia: Kyrios 2013.

Mateo, Carlos. La construcción de la ciencia en la universidad medieval. Apuntes acerca del debate epistemológico en el siglo XIII. Córdoba: Brujas, 2005.

Moorman, John Richard Humpidge. A History of the Franciscan Order from its Origins to the Year 1517. Oxford: Clarendon Press, 1968).

Rovira, Josep M. “Sobre el mètode teològic en Enric de Gand”. Revista catalana de teología 8 (1983) 191-202.

Thomas Aquinas, Sententias. In Scriptum super libros Sententiarum magistri Petri Lombardi episcopi Parisiensis, t. 1, editado por Pierre Mandonnet. Parisiis: P. Lethielleux, 1929.

- Summa theologiae. In Opera omnia iussu impensaque Leonis XIII P. M. edita, t. 4-5: Pars prima Summae theologiae. Romae: Ex Typographia Polyglotta S. C. de Propaganda Fide, 1888-1889.

Tyorinoja, Rebo. "Lumen medium. Henry of Ghent on the Accessibility of Theological Truths". In Medieval Philosophy and Modern Times, editado por Guita Holmström-Hintikka, 161-182. Dordrecht-Boston-London: Kluwer Academic Publishers, 2000.

Vázquez, Isaac. "Repertorio de franciscanos españoles graduados en teología durante la Edad Media”. In Repertorio de Historia de las ciencias eclesiásticas en España, vol. III, 235-320. Salamanca: Universidad. Pontificia de Salamanca, 1971.

Zum Brunn, Emilie, dir. Voici Maître Eckhart, Textes et études. Grenoble: Jérôme Millon, 1994. 